\title{
Aproveitamento de água de chuva para fins potáveis numa escola pública no interior do município de Campo Formoso (BA)
}

\author{
Use of rainwater for potable purposes at a public school inside the \\ municipality of Campo Formoso (BA)
}

\section{Célia Ferreira dos Santos ', Marcio Lima Rios ", Frederico Fonseca da Silva "I, Danielle Finardi Fonseca IV}

\section{RESUMO}

A escassez hídrica, realidade em várias regiões do semiárido brasileiro, associada a irregularidade na distribuição de chuvas, bem como o gerenciamento inadequado de água, tem limitado o avanço socioeconômico e estimulado o conflito pela água. Contudo, tem-se uma boa alternativa para minimizar a ausência desse liquido para as atividades diárias, o aproveitamento de água pluvial, motivo esse que justificou a necessidade de um estudo sobre a viabilidade da adoção de um sistema de captação de água de chuva, a percepção do consumo de água e sua potencialidade para aproveitamento em edificações, numa escola pública no interior do município de Campo Formoso (BA), objetivo principal desse trabalho. A implantação desse sistema além de vir a suprir todas as necessidades da água disponível para o uso contribui, significativamente, no abastecimento e seu uso vinculado a atividades internas da escola. 0 trabalho reuniu dados a partir de pesquisas bibliográficas, mensuração do potencial de captar água de chuva e entrevista com os membros da instituição. Os principais resultados mostraram que existe uma importância em armazenamento desse líquido como prática sustentável de convivência com o semiárido, visando atender as necessidades do consumo e suas vantagens para o bom funcionamento da escola.

Palavras-chave: Semiárido; Escassez da água; Viabilidade.

\section{ABSTRACT}

Water scarcity, a reality in several regions of the Brazilian semi-arid region, associated with irregular distribution of rainfall, as well as inadequate water management, has limited socioeconomic advance and has stimulated conflict over water. However, there is a good alternative to minimize the absence of this liquid

\footnotetext{
'Especialista em Desenvolvimento Sustentável no Semiárido com Ênfase em Recursos Hídricos, IF Baiano. Graduada em Pedagogia e Licenciatura em História. ORCID: https://orcid.org/0000-0003-4312-2473. E-mail: celiaf.ruan@hotmail.com. " Orientador, Graduado em Geografia. Mestre e doutorando em Geografia. Professor e pesquisador, FBaiano. ORCID: http://orcid.org/0000-0002-5032-0390. E-mail: marcio.rios@ifbaiano.edu.br.

III Orientador, Graduado em Engenharia Agronômica. Doutor em Irrigação e Meio Ambiente. Professor e pesquisador, IFPR. ORCID: http://orcid.org/0000-0003-2817-6983. E-mail: frederico.silva@ifpr.edu.br.

Iv Pedagoga, Pós-Graduada em Alfabetização, Educação Infantil. Pedagogia Avançada. ORCID: http://orcid.org/00000002-5049-4729. E-mail: danifinardi1970@gmail.com.
} 
for daily activities, the use of rainwater, which justified the need for a study on the feasibility of adopting a rainwater harvesting system, the perception of water consumption and its potential for use in buildings, in a public school in the interior of the municipality of Campo Formoso (BA), the main objective of this work. The implementation of this system in addition to supplying all the needs of the water available for use contributes significantly to the supply and its use linked to internal activities of the school. The work gathered data from bibliographical research, measurement of the potential to collect rainwater and interview with the members of the institution. The main results showed that there is an importance in storage of this liquid as a sustainable practice of coexistence with the semiarid, aiming to meet the needs of consumption and its advantages for the proper functioning of the school.

Keywords: Semi-arid; Water scarcity; Viability.

\section{INTRODUÇÃO}

Á água encontrada na natureza é um recurso natural limitado, um componente essencial para a sobrevivência da vida no planeta. No entanto, esse recurso tem se tornado cada vez mais escasso, pois em algumas regiões as chuvas aparecem irregulares e, por vezes, em pequena quantidade. Contudo, o problema maior não está somente na predominância do regime pluvial, mas está aliado à falta de gerenciamento eficaz dos recursos hídricos sendo indicado como a causa principal que agrava a disponibilidade da água.

No semiárido brasileiro a escassez hídrica está associada ao uso impróprio das atividades humanas, mas também às adversidades climáticas especificas de regiões secas, principalmente em áreas onde acontecem longos e frequentes períodos de estiagem. Segundo Almeida e Silva (2003), o regime irregular de chuvas acontece em escala espacial, pois há grandes diferenças no índice de chuva nas diversas porções do semiárido brasileiro, e temporal, em que grande parte das precipitações se concentra em poucos meses do ano.

De acordo com Pereira et al. (2007), algumas regiões do Nordeste brasileiro são caracterizadas pela baixa pluviosidade, tornando o índice de chuvas com baixas precipitações anuais. Outrossim, não existe um período contínuo nem para o início nem para o fim da estação chuvosa. A duração dessa estação se concentra de dois a três meses e, raramente, superior a quatro meses. Portanto, mesmo sendo uma 
região cujo clima é definido dessa forma, a captação da água nos períodos chuvosos e sua utilização nos meses de seca, ampliam sua disponibilidade, reduz a possibilidade de escassez e gera maior segurança hídrica, especialmente em famílias que moram no campo.

Em algumas áreas rurais do Nordeste, além da restrição hídrica à agricultura e pecuária, há falta de água para o uso pessoal. E é nessa situação que a captação de água de chuva e armazenamento em cisternas tem sido uma das principais tecnologias utilizadas para o consumo residencial famílias (SUASSUNA, 2018).

Gnadlinger (2011) afirma que a captação de água de chuva é uma prática bastante popular, sendo utilizadas há séculos em várias partes do mundo. A cisterna é uma tecnologia simples e de baixo custo que armazena água de boa qualidade, adequada para o consumo do homem do campo.

Um sistema de captação serve como fonte alternativa que pode ser realizado em unidades residências ou prédios de uso comum, podendo contribuir enquanto instrumento técnico para ampliar a oferta de água e, consequentemente, para reduzir as dificuldades inerentes aos períodos de estiagem em regiões semiáridas ou até mesmo minimizar o impacto do uso desse recurso finito em outras regiões.

Vários estudos têm constatado que o aproveitamento de água de chuva dessa região brasileira tem amenizado o efeito das estiagens, se apresentando como uma tecnologia valiosa de convivência (PEREIRA et al., 2007; PALMIER e GNADLINGER, 2005).

Há diversos problemas que dizem respeito ao uso e manejo das cisternas e de todo sistema de captação de água pluvial. É nesse sentido que atividades que conduzam a instrução e conscientização da população para o uso e um eficiente manejo, são significativamente viáveis e cabíveis no contexto de regiões com menor disponibilidade hídrica.

Para se mudar esse contexto e dar a visibilidade que a captação de água de chuva e armazenamento em cisterna merecem, não basta a tentativa de demonstrar a 
viabilidade dessa proposta apenas pelo efeito visual e dos relatos de experiências bem-sucedidas vivenciadas por famílias residentes em comunidades rurais do semiárido. Além disso, entre outras medidas, é preciso um grande esforço no campo da formação e informação que propicie um entendimento sobre o potencial e o papel da cisterna na solução do abastecimento de água para o consumo humano no meio rural do semiárido (JALFIM, 2001, p. 3).

Portanto, diante dessa problemática, é importante que a captação da água da chuva seja uma proposta de política pública para que seja implantada também na rede educacional de ensino como um projeto unido a outras instituições ou organizações não governamentais.

Dessa forma, a importância do uso da água pluvial nesses estabelecimentos servirá como instrumento não apenas para reduzir os gastos e resolução de problemas relacionados aos extremos pluviométricos, mas também como ferramenta de educação.

Assim, a captação de água de chuva para uso em escolas, ainda pouco utilizado na prática, é um tema discutido também por diversos autores, entre eles Silva (2003); Almeida e Oliveira (2009); Almeida e Gomes (2011); Silva Neto et al. (2012).

Em tempo de crise hídrica a instalação e uso de cisternas para a captação de água da chuva, torna-se uma ferramenta de conscientização para a comunidade escolar, promove a formação de agentes de mudanças e multiplicadores de ações sustentáveis.

Diante do exposto, cabe ressaltar que, é de extrema importância desenvolver estratégias e conceitos relacionados à água, desenvolvendo ações voltadas para a educação ambiental, pois essas temáticas possibilitam trabalhar esses conteúdos não somente na sala de aula, mas no ambiente escolar como um todo, buscando promover a melhoria da qualidade de ensino e a promoção da sustentabilidade socioambiental nas unidades escolares.

O presente estudo apontou a viabilidade da implantação de um sistema com uso de técnica de captação de água de chuva, e avaliou a percepção da comunidade escolar em relação ao aproveitamento e consumo de água numa escola pública no 
estado da Bahia. Portanto, espera-se que o trabalho sirva como apoio para instituições de ensino localizadas em áreas semiáridas distantes de fontes hídricas e que apresentam sérios problemas com abastecimento de água.

\section{MATERIAIS E MÉTODOS}

De acordo com Gerhardt e Silveira (2009), metodologia científica é o estudo sistemático e lógico dos métodos empregados nas ciências, seus fundamentos, sua validade e sua relação com as teorias científicas. Por sua vez, método é o caminho em direção a um objetivo; metodologia é o estudo do método, ou seja, é o corpo de regras e procedimentos estabelecidos para realizar uma pesquisa científica.

Marconi e Lakatos (2003) definem o método como o conjunto das atividades sistemáticas e racionais que, com maior segurança e economia, permitem traçar o caminho a ser seguido, detectando erros e auxiliando as decisões do pesquisador para alcançar o objetivo da pesquisa.

O município escolhido para realização da pesquisa foi Campo Formoso (BA), em uma escola pública do Ensino Fundamental II, situada no bairro Bela Vista, no distrito de Poços, comunidade localizada a 9,0 km da sede. A cidade de Campo Formoso encontra-se a $410 \mathrm{~km}$ da capital baiana e, de acordo com o censo demográfico (IBGE, 2016) possui 73.118 habitantes (o distrito de Poços possui, aproximadamente, 3.753 habitantes).

A primeira etapa da pesquisa consistiu no levantamento de informações acerca de dados bibliográficos, através da utilização de materiais já publicados sobre o tema, por meio da revisão da literatura em livros, artigos científicos, com base na análise de fontes secundárias que abordaram o tema de diferente maneira.

Em seguida, foi feita a investigação do consumo de água na unidade escolar, com conversas informais, e pela coleta de dados. Realizou-se a pesquisa de campo 
com a utilização das técnicas de observação in loco, e na aplicação de questionário semiestruturado.

Para alcançar os resultados pretendidos, foi adotada uma abordagem qualiqualitativa (GUNTHER, 2006). Realizou-se um estudo buscando opiniões, considerando a dinâmica existente entre a realidade e o sujeito, dos colaboradores, procurando ouvi-los, explorar suas ideias, na realização das entrevistas e questionários, sistematizando os resultados em gráficos e tabelas, e os números obtidos para analisá-los.

No desenvolver desta pesquisa foi aplicado questionários individuais, composto por 10 questões objetivas de caráter quali-quantitativo, para 133 colaboradores entre eles, alunos, professores, servidores.

Fez-se uma análise da percepção e do ponto de vista da comunidade escolar a respeito da água, sobre como eles fazem uso, se acham que tem desperdício, se a água para o consumo tem qualidade e sobre a possibilidade de captação de água de chuva na escola.

O roteiro da entrevista teve a pretensão para a percepção da comunidade escolar sobre a importância do uso racional da água e benefícios da captação da água da chuva.

Também foi organizada entrevista com os responsáveis no recebimento da água no colégio e aos motoristas do caminhão-pipa, onde os dados referentes ao consumo de água da escola também foram levantados.

Como referência, realizou-se um seminário local, visando esclarecer a importância de captar água de chuva na escola e apresentar os resultados da pesquisa.

No que se refere aos dados pluviométricos anuais da região em que a escola está inserida foi realizado um levantamento através da verificação dos dados secundários fornecidos pela Agência Nacional de Água (ANA, 2017). 
A localidade de Poços não possui estação pluviométrica oficial. Portanto, para estabelecer o índice pluviométrico anual foi utilizada uma Ponderação do Inverso da Distância (IDW - Inverse Distance Weighted) a partir de localidades próximas que possuem dados de estações pluviométricas onde, de acordo com Marcuzzo et al. (2011), a interpolação por IDW determina os valores dos pontos usando uma combinação linear ponderada dos pontos amostrados. O peso de cada ponto é o inverso de uma função da distância. Isso quer dizer que quanto maior for a distância do ponto a ser interpolado, menor será o peso na equação.

Assim, foram utilizados dados das três estações no entorno de distrito de Poços.

Tabela 1 - Estações Meteorológicas no entorno de Poços, no município de Campo Formoso (BA)

\begin{tabular}{lcc}
\hline \multicolumn{1}{c}{ Estação Meteorológica } & Distância de Poços (Km) & Índice pluviométrico (mm/ano) \\
\hline Campo Formoso & 8,1 & 1.035 \\
Fazenda Oco d'Água & 31,5 & 574 \\
Brejo da Caatinga & 48,2 & 479 \\
\hline
\end{tabular}

Fonte: dados pluviométricos acessados no endereço eletrônico hidroweb (ANA, 2017). Tabela organizada pelos autores.

Foi feito posteriormente, a mensuração da área do telhado do ginásio de esportes, coberto com telha de alumínio; e, do telhado do colégio, coberto com telha de cerâmica. Nesse sentido, utilizaram-se trenas para medir em campo o comprimento e altura das áreas de cobertura de cada estabelecimento. Essa atividade deu-se como resultado o levantamento das dimensões da edificação para cálculo da área $\left(\mathrm{m}^{2}\right)$ do telhado.

Portanto, para calcular o potencial de captação e armazenamento de água de chuva foi necessário a atribuição dos coeficientes de escoamento superficial nos telhados de alumínio (quadra) e cerâmica (colégio), de acordo com informações de Silva et al. (1984) e Silva Neto et al. (2012). 
O cálculo para saber o volume de água a ser captado nos telhados, foi realizado de acordo com Silva et al (1984) e Almeida e Silva (2003), conforme Fórmula:

Volume a ser captado $=$ Total de chuva anual $(\mathrm{mm}) \times$ área do telhado $\left(\mathrm{m}^{2}\right) \times$ coeficiente de escoamento

\section{RESULTADOS E DISCURSÕES}

\subsection{A captação de água de chuva}

Os resultados para o índice pluviométrico anual do distrito de Poços, para a área do telhado e o potencial de captação de água de chuva no Colégio Municipal Dr. Rômulo Galvão estão apresentados na Tabela 2.

Tabela 2 - Potencial de Captação de Água de Chuva nos telhados do Colégio Municipal Dr. Rômulo Galvão no Distrito de Poços - Município de Campo Formoso (BA)

\begin{tabular}{ccccc}
\hline Local & Índice Pluviométrico Anual Área do Telhado & Coeficiente de & Potencial de \\
$(\mathrm{mm})$ & $\left(\mathrm{m}^{2}\right)$ & $\begin{array}{c}\text { Captação } \\
\text { Escoamento }\end{array}$ & $\begin{array}{c}\left.{ }^{1}\right) \\
\left(\mathrm{m}^{3} \cdot \mathrm{ano}^{-1}\right)\end{array}$ \\
\hline
\end{tabular}

Ginásio 886

$1.496,0 \quad 0,90$

$1.192,91$

Prédio Escolar 886

946,8

0,85

713,03

Total

$1.905,94$

(1) Coeficiente de escoamento estabelecido de acordo com Silva et al. (1984) e Silva Neto et al. (2012). Fonte: Organizado pelos autores.

Para captação de água de chuva é um dado importante, por aumentar o potencial de abastecimento hídrico e viabilizar diversos projetos para uso da água, principalmente para uso humano quando a outra opção é servir-se de água 
abastecida por caminhões pipa, muitas vezes com potabilidade duvidosa. Conforme expresso na Tabela 2, o volume de água captada se aproxima de 2.000 .000 de litros por ano, valor bastante significativo.

Sabe-se que a água que chega até Poços vem de uma barragem e a gravidade do problema de desabastecimento chega a níveis críticos, pois o desperdício é proveniente do desvio de água nas propriedades rurais por onde passa a adutora. Em muitos pontos a água é desviada da tubulação para abastecer currais e até mesmo irrigar cultivos. Por esses e outros motivos, o abastecimento no Colégio em estudo é bastante irregular e que já ocorreram corte de água por vários meses, principalmente nos períodos de estiagem prolongada na região.

Nos períodos críticos em que a água não chega na escola, o abastecimento é realizado através de caminhão pipa, também disponibilizado pela Prefeitura Municipal. O custo da água de um caminhão com capacidade de 8.000 litros é de $\mathrm{R} \$ 130,00$.

Para atender a demanda da escola há uma necessidade de 16.000 litros de água por semana, totalizando um valor de $\mathrm{R} \$ 260,00$, dando um volume aproximado de consumo de 64.000 litros mensais, com um custo de $R \$ 1.040,00$, sendo equivalente a 768.000 litros anuais que correspondem a $R \$ 12.480,00$ de despesa para 0 abastecimento da escola.

Através da Tabela 3, de gastos, observa-se o abastecimento de água por litros em caminhão pipa, obtendo-se assim o custo da água para o funcionamento do colégio.

Tabela 3 -Tabela de gastos c/ abastecimento por caminhão pipa

\begin{tabular}{llll}
\hline & Semana & Mês & Ano \\
\hline Financeiros $(\mathrm{R} \$)$ & 260,00 & $1.040,00$ & $12.480,00$ \\
\hline
\end{tabular}




\begin{tabular}{llll}
\hline $\begin{array}{l}\text { Abastecimento de } \\
\text { água (litros) }\end{array}$ & 16.000 & 64.000 & 768.000 \\
\hline
\end{tabular}

Fonte: Organizado pelos autores.

Considerando esse cálculo apresentado na Tabela 3, observa-se que o volume anual captado de água de chuva (Tabela 2) seria suficiente para atender toda a demanda da escola. Ou melhor, capta-se, em potencial, $148 \%$ a mais do que a quantidade recebida através de caminhões pipa por ano.

A título de comparação e focando na valorização da captação de água de chuva, o volume captado anualmente seria o equivalente a 250 caminhões pipas (de 8.000 litros) e uma economia significativa para a prefeitura de Campo Formoso.

Estes dados mostram o grande potencial de captação de água da chuva, fazendo uma diferença considerável, pois a quantidade de água captada por si só, seria suficiente para o abastecimento da escola, desconstruindo a possibilidade de uma dependência de caminhões pipas, da verdadeira "indústria da seca" e das irregularidades no sistema de abastecimento por tubulação.

Conforme Vasconcelos e Ferreira (2007), a possibilidade de usar a água de chuva é fator indispensável em residências que provavelmente resultará na redução do fornecimento de água gerenciada pelas companhias de saneamento e na demanda dos custos para utilizar a água potável. O mesmo ocorrendo em algumas instituições, que em sua grande maioria, são mantidas através de escassos recursos financeiros. Certamente a construção de sistema de captação de água de chuva (calhas, tubulações e cisternas) demanda relativo investimento inicial, mas com significativo retorno econômico e ambiental: primeiro pela redução nos custos com o funcionamento da unidade escolar; e, segundo ao aproveitamento de uma importante fonte de água (chuva) em um contexto climático associado a constantes períodos de escassez hídrica. 
3.2 0 ponto de vista dos alunos sobre a situação hídrica na escola e a possibilidade de um sistema de captação de água de chuva.

Foi perguntado para os alunos se estão satisfeitos com a água que estão consumindo. Todos os entrevistados responderam que "não" demonstrando total insatisfação com a atual condição hídrica na escola. Essa insatisfação está associada, provavelmente, a constante falta de água existente na escola e também à qualidade da mesma quando abastecida por caminhões pipa, pois foi relatado que água é salobra e possui aspectos de cor amarelada.

Para reforçar essa interpretação, também foi perguntado se a água consumida na escola dispõe de uma quantidade e qualidade adequada para as necessidades humanas. A maioria dos alunos (64\%), responderam que "não" é adequada para o consumo; 34\% responderam "em parte", sendo indicativo de dúvida gerada, certamente, pela existência de grandes problemas enfrentados na comunidade escolar; e, apenas 2\% responderam que "sim", de acordo com a Gráfico 1.

Gráfico 1 - Opinião da comunidade escolar em relação a quantidade e qualidade da água. Pergunta: a água consumida na escola dispõe de uma quantidade e qualidade adequada para as necessidades humanas?

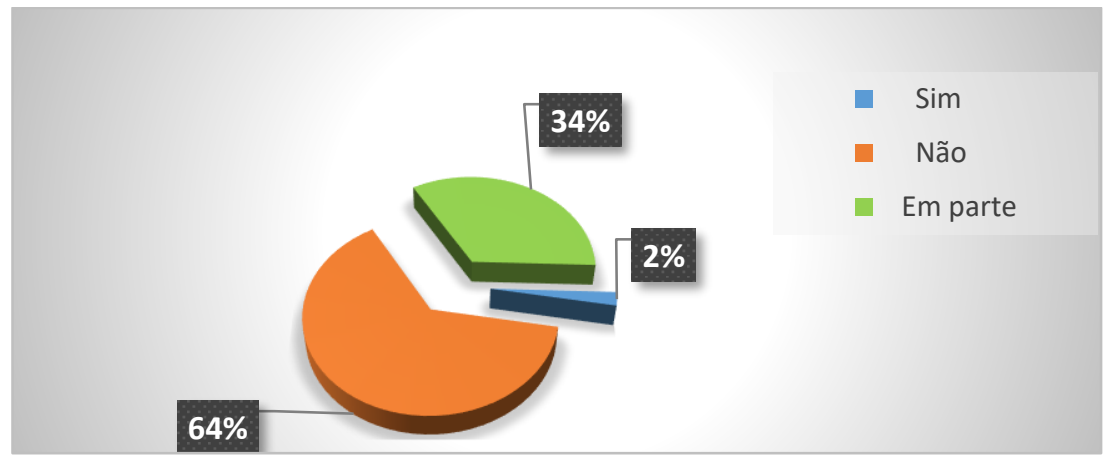

Fonte: Organizado pelos autores.

Os dados mostram que os estudantes reconhecem a existência de diversos problemas, tanto em relação à qualidade, quanto em relação a quantidade de água disponível. Várias justificativas foram dadas pelos entrevistados: Comentaram que a 
água que chega à escola não tem nenhum tratamento; é "bastante poluída"; e, tem um "gosto estranho". Vale frisar que para a água ser considerada apta para consumo humano deve ser tratada e obedecer aos padrões mínimos de potabilidade, como o índice de coliformes fecais e totais, de minerais, além de outros parâmetros, conforme estabelece as normas do CONAMA (2005) que dispõe sobre a classificação dos corpos de água e diretrizes ambientais para o seu enquadramento.

Boa parte dos alunos considera que "a água não é suficiente para o consumo" trazendo transtornos para as atividades escolares, como o cancelamento das aulas, prejudicando diretamente a aprendizagem, contribuindo para o baixo desempenho escolar e comprometimento dos conteúdos. Outro transtorno citado pelos estudantes diz respeito a ausência de merenda escolar, pois com a falta de água não há funcionamento da cozinha e cantina na escola.

O diagnóstico foi realizado conforme a concepção dos alunos que vivenciam essa realidade em quase todo seu cotidiano dentro da escola, que por conta da ausência desse líquido tão indispensável, dificulta o trabalho para uma educação com sucesso.

Embora o abastecimento de água na escola nos anos de 2016 e 2017 tenha sido através de caminhão pipa, para o ano de 2018 o abastecimento retornou para o sistema convencional. Nesse contexto, foi perguntado aos estudantes sobre qual seria a alternativa mais viável, como complemento ao sistema de abastecimento, para prevenir a escassez de água na escola. Os resultados apresentados na Tabela 4, revelam que a maioria dos alunos da escola $(78,13 \%)$, apontam a captação de água de chuva como alternativa mais viável. Alguns dos entrevistados (15,62\%), optaram pela alternativa correspondente ao incentivo para a educação ambiental e redução do consumo, enquanto, que $6,25 \%$ escolheram a construção de barragens como alternativa mais viável. 
Tabela 4 - Resposta dos estudantes em relação a alternativa mais viável, como complemento ao sistema de encanamentos (adutoras e tubulações), para prevenir a escassez de água na escola

\begin{tabular}{lr}
\hline \multicolumn{1}{c}{ Item } & Percentual (\%) \\
\hline Captar água de chuva & 78,13 \\
Incentivo para a educação ambiental e redução do consumo & 15,62 \\
Construir barragens & 6,25 \\
\hline
\end{tabular}

Fonte: Organizado pelos autores.

Esses dados apontam que existem entre os estudantes, informações sobre a viabilidade da captação de água de chuva em telhados, mostrando que há um reconhecimento e possível aceitação dessa tecnologia social no espaço escolar.

A próxima pergunta foi sobre o ponto de vista dos estudantes em relação aos benefícios que a construção de cisternas pode gerar na escola. Para responder essa pergunta os mesmos poderiam escolher mais de 1 opção em relação aos benefícios apresentados como item na questão. De acordo com o Gráfico 2, tem-se a: Opção 1. Nenhum benefício; Opção 2. Benefício ambiental, associado ao aproveitamento de água no contexto do semiárido; Opção 3. Benefício social, associado a oferta de água gratuita para as famílias; e, Opção 4. Benefício econômico: economia de recursos financeiros para escola e prefeitura. 
Gráfico 2 - Itens apontados pelos estudantes em relação aos benefícios com a construção de cisternas na escola

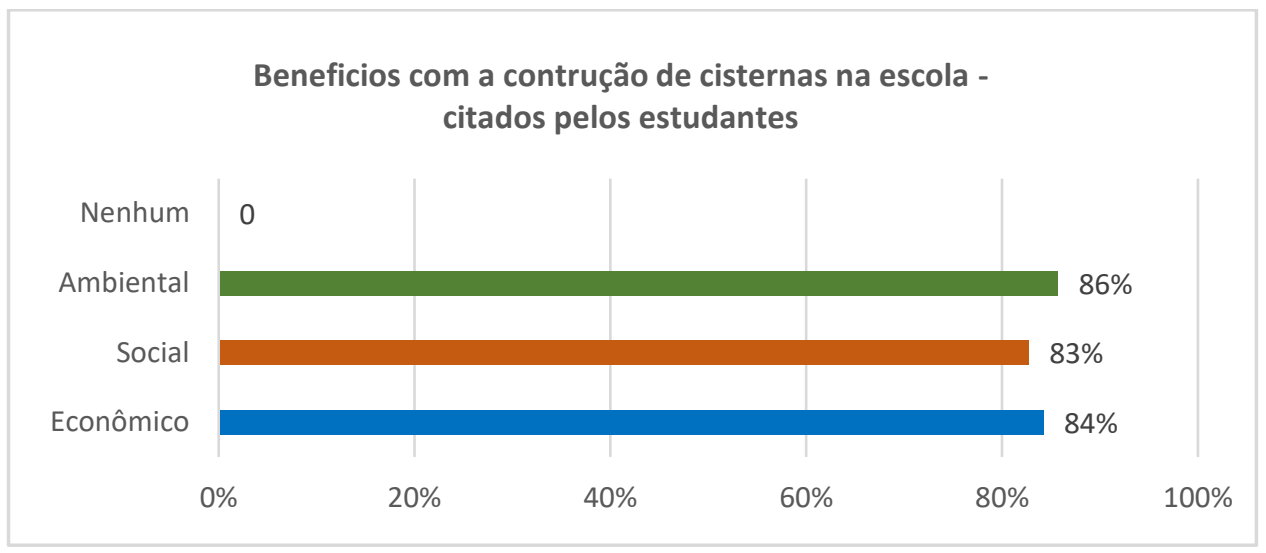

Fonte: Organizado pelos autores.

De acordo com o Gráfico 2, verifica-se que os benefícios ambiental, econômico e social foram amplamente apontados pelos estudantes, sendo o "ambiental" presente em $86 \%$ das respostas, "econômico" em $84 \%$ e "social" em 83\% das respostas. Não foi apontado o item "nenhum". Há de fato, entre os estudantes a percepção de que as cisternas trazem benefícios para a comunidade escolar.

O sistema de captação de água de chuvas através dos telhados e armazenamento em cisternas é uma excelente tecnologia alternativa para auxiliar no abastecimento de água da escola. Há entendimento e aceitação da comunidade estudantil na implantação de um sistema de captação de água de chuva, em face da crise de abastecimento que afeta gradativamente a escola e aos benefícios que as cisternas podem trazer.

\subsection{0 ponto de vista dos professores sobre a situação hídrica na escola e a} possibilidade de um sistema de captação de água de chuva

Foi perguntado para 27 professores se estão satisfeitos com a água que estão consumindo. Os resultados apresentados revelam que $89 \%$ dos entrevistados 
optaram pela alternativa correspondente a "não", demonstrando grande insatisfação com a atual condição hídrica na escola. Em relatos dos docentes é apontado que a água não é de boa qualidade, não possui tratamento e não é adequada para o consumo diário. Foram relatadas sobre a cor observada na água (amarela ou de cor escura). A insatisfação também está associada a constante falta de água, que causa a suspensão das aulas e, consequentemente, atrasos na aprendizagem dos alunos. Outros 7\% responderam "sim", estão satisfeitos com a água que estão consumindo. Um dos professores explicou: "essa é a única água que temos para consumir na escola, portanto não tem outra opção, é a única".

\section{Gráfico 3 - Satisfação dos professores com a atual situação da água na escola}

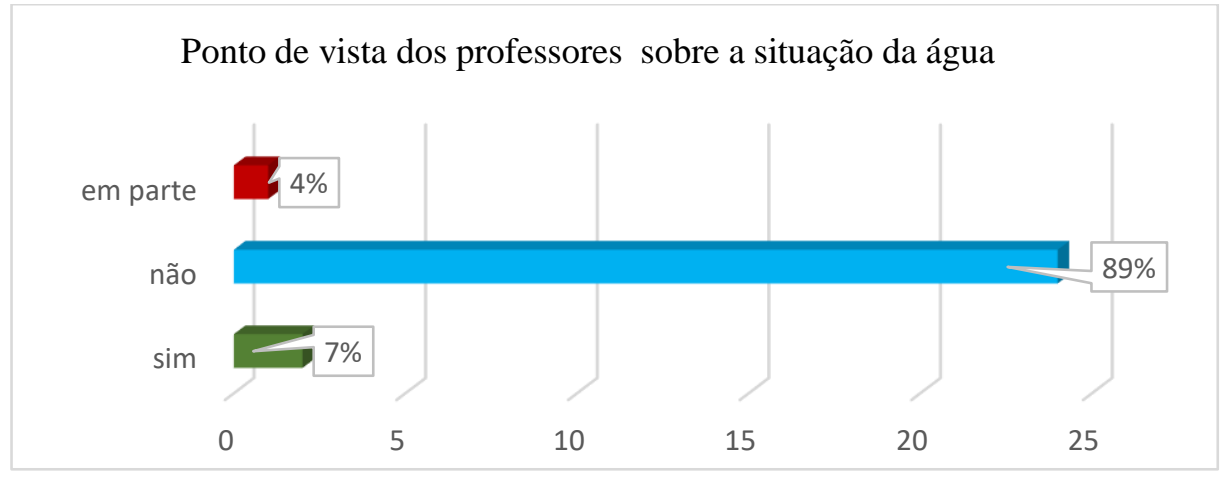

Fonte: Organizado pelos autores.

Apenas 4\% escolheu a opção "em parte". Um dos professores relata que “consumimos água pela necessidade, para realização das tarefas internas da escola, mas que a água não chega em condições adequadas para consumir, portanto não está totalmente apropriada para o uso dentro da escola". Os demais entrevistados comentaram ainda que esse líquido tão importante apresenta impurezas, não passa por tratamento químico, não é potável e, por conta da irregular disponibilidade, as atividades pedagógicas, esporadicamente, deixam de ser realizadas.

Com o abastecimento irregular, havia a presença constate do carro pipa, mas muitas vezes o volume hídrico que chegava na escola não correspondia a quantidade 
necessária para o consumo, persistindo a falta de água. O reabastecimento por carro pipa era demorado por conta de outras demandas do órgão público (prefeitura) durante a estiagem. Portanto, aconteciam os prejuízos na realização das atividades escolares, principalmente para os alunos, pois a falta do liquido afetava o preparo da merenda escolar e inviabilizava a utilização dos banheiros.

Considerando o relato de grande parte dos professores percebe-se que a situação hídrica no colégio compromete a qualidade do ensino e pode afetar até mesmo a saúde da comunidade escolar. Esse é um dado muito preocupante, uma vez que o ambiente escolar deve, obrigatoriamente, proporcionar bem-estar e condições mínimas para o aprendizado.

Os professores foram questionados também sobre qual o principal problema em termo da escassez de água na escola. Observa-se no Gráfico 4 que 52\% dos entrevistados afirmam ser "as chuvas irregulares" como o principal fator da escassez hídrica no colégio. Outros $41 \%$, acreditam que a problemática da crise hídrica é resultante de estratégias errôneas, ou falta de ações, por parte do poder público, que não atendem as necessidades da comunidade escolar no que diz respeito ao sistema de abastecimento. Para 7\% dos professores, "outros", correspondente ao abastecimento insuficiente, má distribuição, como fatores responsáveis pela falta de água no colégio. 
Gráfico 4 - Itens apontados pelos professores em relação a problemática de escassez de água na escola

Opinião dos professores quanto as causas da escassez de água na escola
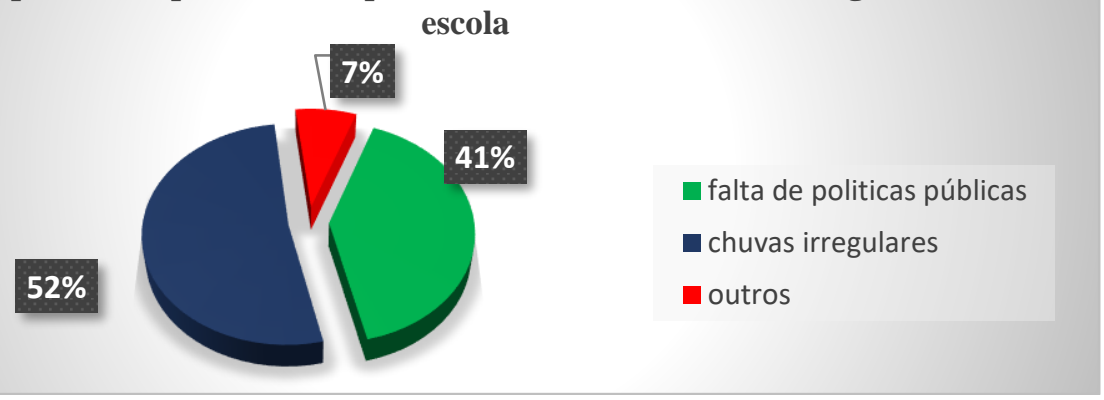

Fonte: Organizado pelos autores.

Apesar da diferença ser pouco significativa, a maioria dos docentes acreditam que o grande problema está na falta de chuva ou na irregular distribuição da pluviosidade, isto é, está nas condições naturais do próprio semiárido. De fato, a falta de água ocorre nos momentos de "seca", onde as chuvas são escassas. É conveniente acrescentar que o poder público tem sua responsabilidade diante da escassez de água no estabelecimento escolar, pois é de sua competência garantir, suprir e manter esse abastecimento (RIBEIRO, 2015). O poder público possui meios técnicos para impedir o desabastecimento, tanto na melhoria da gestão do recurso hídrico, como ampliação do sistema da captação de água.

Foi perguntado aos docentes sobre as suas contribuições para reduzir a escassez de água na escola. A pergunta foi aberta, visando coletar as ações dos docentes. Foram observadas diversas respostas, todas associadas à conscientização e sensibilização dos alunos, e foram assim agrupadas: I. "Sensibilizar os alunos sobre práticas e atitudes sustentáveis", 12,5\%; "Sensibilizar sobre a reutilização da água", 12,5\%; e, III. "Sensibilizam os alunos a usarem a água de forma consciente (economia de água/evitar desperdício) ", 75\%.

As opiniões relatadas apontam para procedimentos de uma boa conduta, e que estejam voltadas para uma educação ambiental que contemple a aquisição de 
hábitos, valores, mudanças de atitudes e comportamentos, voltados principalmente para o fim do desperdício e uso consciente da água, tanto no interior da escola, quanto na vida. Os professores afirmaram que estão sempre falando sobre essa problemática.

Foi perguntado também sobre quais melhorias devem ser feitas em sua comunidade escolar visando a resolução do problema da escassez da água. A pergunta foi aberta, visando observar o ponto de vista dos docentes. As respostas foram agrupadas em três itens e apresentadas na Tabela 5.

Tabela 5 - Resposta dos professores sobre quais melhorias devem ser feitas em sua comunidade escolar visando a resolução do problema da escassez da água

\begin{tabular}{lc}
\hline Opção & Percentual (\%) \\
\hline Captação de água e cisterna & 59,3 \\
Abastecimento regular & 25,9 \\
Fim do desperdício/Reutilização de água & 14,8 \\
\hline
\end{tabular}

Fonte: Organizado pelos autores.

Diante das respostas apresentadas na Tabela 5, confirma-se que a maioria dos docentes (59,3\%), apontou o sistema de captação de água de chuva e armazenamento em cisternas. Para 25,9\% dos entrevistados o abastecimento por sistema convencional deve ser regularizado e adequado para as necessidades da escola. Enquanto que 14,8\% indicaram que é necessário evitar o desperdício e reaproveitar a água, para utilização em banheiros e na limpeza dos pisos, por exemplo. Esses dados apontam que existe entre os entrevistados, opiniões diferentes, mas predominou a captação de água de chuva. Esse ponto reforça que a comunidade interna entende e aceita o uso de cisternas com alternativa capaz de contribuir na resolução dos problemas de escassez hídrica na escola. 
Foi perguntado aos professores, quais atividades despertam o interesse para aulas práticas utilizando um possível sistema de captação de água de chuva com armazenamento em cisternas. As alternativas eram: horticultura, regar jardim, atividade de pesquisa e projetos, e outras, sendo que os professores poderiam marcar mais de uma opção (Gráfico 5).

\section{Gráfico 5 - Itens apontados pelos professores sobre atividades que despertam interesse} nas aulas práticas com a captação de água de chuva

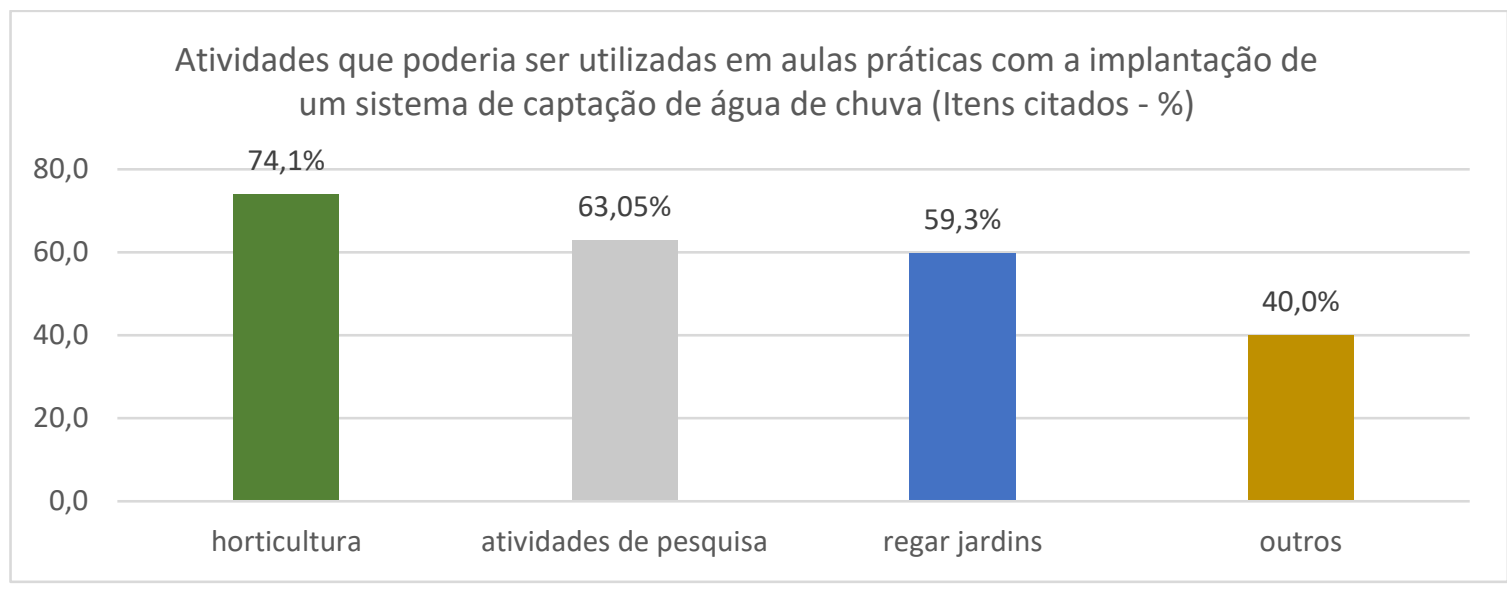

Fonte: Organizado pelos autores.

Interessante notar que, mesmo sendo docentes, e que na sua ampla maioria desaprovam o atual consumo de água servido por carros pipa, quando da possibilidade de uso dessa água captada da chuva, deriva para outros fins que não a dessedentação humana.

Assim, após o descarte para consumo humano, o Gráfico 5 mostra que o item "horticultura" foi citado por 74,1\% dos professores; em seguida o item "atividade de pesquisa e projetos" citado por 63,0\%. O terceiro item foi "regar jardins" citado por 59,3\%; O item "outros" contemplou atividades como: cálculos, perfis socioambientais de usuários e análises química, que em conjunto foi citado por 40,0\% dos entrevistados. 
Analisando ainda o Gráfico 5, é perceptível a predominância da horticultura enquanto elemento de maior menção. A abordagem prática desse elemento se dá por meio de atividades envolvendo cultivo de hortaliças, levando a produção e aproveitamento de legumes no âmbito escolar, como forma de melhoria da alimentação consumida no Colégio. Nesta abordagem é notório que a utilização de horta propicia a vivência enriquecedora no ambiente escolar, haja vista que a estreita relação desta com a vivência cotidiana dos alunos (em sua totalidade imersos e oriundos do meio rural). Tal abordagem possibilita o desenvolvimento da temática da captação de água de chuva como fator importante para contextualizar as aulas, haja vista a necessidade de provimento das hortas com recursos hídricos com base sustentável. Assim sendo, esta alternativa "horticultura" é apontada como melhor forma de despertar o interesse no aluno para as práticas dentro de sala de aula.

Já o item citado como "atividade de pesquisa e projetos" certamente está relacionado a importância de trabalhar em sala com a prática pedagógica acerca do tema água no contexto da educação ambiental, abordando alternativas sustentáveis de captação e armazenagem.

Para o item citado como "regar jardins" tem também importante contribuição com a utilização do sistema de captação e armazenagem de águas pluviais, pois os jardins trazem benefícios ao ambiente escolar agindo de forma impactante e reduzindo a necessidade de climatização artificial diminuindo a temperatura do ambiente. Muito embora se reconheça que essa água captada, de excelente qualidade, poderia se destinar a fins mais nobres e, o descarte ou reuso da mesma vir a servir à esse propósito, principalmente quanto ao plantio de árvores no entorno do colégio, preferencialmente, frutíferas.

A última pergunta foi: se o professor tivesse que trabalhar com educação ambiental e os benefícios de captação de água de chuva dentro da sua disciplina, que abordagem ele faria. As respostas estão na tabela a seguir. 
Tabela 6 - Tipo de abordagem que os professores fariam a partir da educação ambiental e os benefícios da captação de água de chuva dentro da sua disciplina

\begin{tabular}{lc}
\hline Abordagem & Percentual (\%) \\
\hline Conscientização a partir de assuntos específicos & 69,6 \\
Projetos articuladores & 30,4 \\
\hline
\end{tabular}

Fonte: Organizado pelos autores.

Pode-se observar que $69,6 \%$ dos entrevistados apontaram que trabalhariam a partir de temáticas especificas em cada disciplina, durante suas aulas, visando a conscientização sobre a importância da cisterna; 30,4\% apontaram que fariam a partir de projetos articuladores, organizados em forma de atividades interdisciplinares. Nesta última questão os entrevistados expuseram suas opiniões sobre a oportunidade de trabalhar com a temática educação ambiental e os benefícios da captação de água de chuva nas disciplinas que cada um leciona.

A maioria dos professores reconhece a importância em trabalhar a temática da captação de água de chuva dentro dos conteúdos de sua disciplina e não apenas em forma de projetos temáticos/articuladores desenvolvidos na escola. Vale salientar a importância de ações educativas de sensibilização que proporcione aos alunos a adoção de práticas sustentáveis dando importância ao uso da cisterna. Desta forma, educa-os e incentiva-os a refletir sobre suas ações, a valorizar o meio ambiente escolar e os recursos naturais.

Nessa questão, cada professor procurou responder como poderia utilizar suas metodologias no contexto dessa temática tão importante para o semiárido. Falaram ainda que é importante conscientizar toda a comunidade escolar sobre o benefício da construção de um sistema de captação de água de chuva no colégio, pois com a sua implantação permitirá a inclusão da dimensão ambiental no currículo escolar. 


\section{CONCLUSÃO}

Ao analisar e refletir sobre os resultados obtidos com esta pesquisa, conclui-se que a captação de água de chuva em telhados do colégio Rômulo Galvão, situado no Distrito de Poços (BA), valoriza as tecnologias adequadas para o convívio com o semiárido brasileiro.

Diante desses resultados percebe-se que, de modo geral, grande parte dos entrevistados ao responderem os questionários aponta uma grande insatisfação com a água consumida no colégio e mostraram ter consciência da relevância da construção de cisterna para elevar a oferta de água de boa qualidade. Com a percepção de que essa tecnologia social aumenta a oferta de água assegurando-a o consumo da escola, contribui assim, para a melhoria da qualidade de vida.

Pode-se inferir que a utilização de coleta de água de chuva na escola pode se tornar viável desde que se faça uma investigação de forma precisa trazendo uma conscientização ambiental para todos os envolvidos, contribuindo para a preservação dos recursos hídricos.

Estudos desse tipo devem apontar para as possibilidades e meios de preservação e inovação em um ambiente escolar, pois reforça o compromisso das instituições de ensino com o desenvolvimento regional sustentável, além de que, é na escola que se constrói o aprendizado como base para formação de cidadãos conscientes diante das problemáticas que suas ações exercem sobre a natureza. Apesar de ser um tema específico, é muito relevante para o conhecimento e experiência de todo profissional, pois retrata um assunto muito atual, que é a escassez de água, não somente no semiárido, mas também em outras regiões do Brasil e do mundo.

O referido trabalho traz uma reflexão sobre a importância de discutir esse tema com os professores, alunos e funcionários do Colégio Municipal Dr. Rômulo Galvão, 
para entendermos as ideias e sugestões sobre o consumo da água e como deve ser o seu aproveitamento.

O contexto educacional precisa de iniciativas como essas, que ajudem o homem de modo geral a conscientizar-se da importância do racionamento de água, de utilizála de modo adequado evitando problema nas secas prolongadas.

A iniciativa deve ser considerada uma sugestão para que seja difundida a partir de políticas públicas. Na sala de aula ou fora dela, os alunos devem participar e aprender iniciativas de maneira que percebam a importância de cuidar e conservar tudo que faz parte do meio ambiente.

Dessa forma, entende-se que tecnologias sociais de convivência com o semiárido, sejam incluídas no currículo escolar das escolas da região semiárida brasileira, para que sejam desenvolvidas atividades que possam contribuir no desempenho dos alunos e no desenvolvimento da unidade escolar, estimulando a comunidade a adotarem tecnologias que contribuem para o enfrentamento da escassez hídrica nessa porção regional do nordeste brasileiro.

\section{REFERÊNCIAS}

ALMEIDA, H.A.; SILVA, L. Estimativa do potencial para captação de água de chuva no brejo paraibano. In: $4^{\circ}$ Simpósio Brasileiro sobre Captação e Manejo de Água de Chuva, Anais... Juazeiro (BA). ABCMAC, 9-11 de julho de 2003.

- Modelo de distribuição de chuvas para a cidade de Areia, PB. In: I Congresso Intercontinental de Geociências, Fortaleza (CE), 2004, Anais, CD-ROM.

ALMEIDA H.A.; OLIVEIRA, G.C.S. Potencial para a captação de água de chuvas em catolé de Casinhas-PE. $7^{\circ}$ Simpósio Brasileiro sobre Captação e Manejo de Água de Chuva, Anais... Caruaru (PE). 2009.

ALMEIDA H.A.; GOMES, M.V.A. Potencial para a captação de água da chuva: alternativa de abastecimento de água nas escolas públicas de Cuité (PB). XVII Congresso Brasileiro de Agrometeorologia. 2011. 
ANA - AGÊNCIA NACIONAL DE ÁGUAS. Sistemas de Informações Hidrológicas (Hidroweb). Séries Históricas. $\quad 01040009 . \quad$ Dstação isponível em: http://hidroweb.ana.gov.br/Estacao.asp?Codigo=1040009\&CriaArq=true\&TipoArq=2. Acesso em 31 de agosto de 2017.

CONAMA - Conselho Nacional do Meio Ambiente. Resolução CONAMA 357, Ministério do Meio Ambiente. Disponível no endereço eletrônico: http://www2.mma.gov.br/port/conama/res/res05/res35705.pdf e acessado em 28.03.2018.

GNADLINGER, J. Captação de água da chuva: uma ferramenta para atendimento às populações rurais inseridas em localidades áridas e semiáridas. In: Medeiros, S.S.; Gheyi, H.R.; Galvão, C.O.; Paz, V.P.S. (eds). Recursos Hídricos em Regiões Áridas e Semiáridas. Campina Grande: INSA/UFRB, 2011. Cap. 11, p 325-357. Acesso dia 23/01 2018.

GERHARDT, T.E.; SILVEIRA, D.T. Métodos de pesquisa. Rio Grande do Sul: UFRGS, 2009.

GÜNTHER, H. Pesquisa qualitativa versus pesquisa quantitativa: esta é a questão? In: Revista Psicologia: teoria e pesquisa. Brasília: Editora da UnB, v.22, n.2, p.201-210, mai./ago., 2006.

IBGE - Instituto Brasileiro de Geografia e Estatística, Dados Estatísticos Cidade: Campo Formoso/BA. 2016. Disponível em http://cidades.ibge.gov.br/xtras/perfil.php?codmun=290600, Acesso em 22/02/2017.

JALFIM, F.T. Considerações sobre a viabilidade técnica e social da Captação e armazenamento da água da chuva em cisternas rurais na região semi-árida brasileira. Recife (PE). Disponível em: $\quad$ http://www.abcmac.org.br/files/simposio /3simp_felipe_consideracoessobreviabilidadetecnica.pdf. Acesso dia: 05/01/2018.

MARCONI, M.A.; LAKATOS, E.M. Fundamentos de metodologia científica. 5. ed. São Paulo: Atlas, 2003.

MARCUZZO, F.F.N.; ANDRADE, L.R.; MELO, D.C.R. Métodos de Interpolação Matemática no Mapeamento de Chuvas do Estado do Mato Grosso. Revista Brasileira de Geografia Física, v.4, n.4, p. 793-804, 2011. Disponível em: http://www.ufpe.br/rbgfe/index.php/revista/article/view/197/204. Acesso em: 18. jan.2018.

PALMIER, L.R.; GNADLINGER, J. (2005). Tecnologias de captação e manejo de água de chuva para o semi-árido brasileiro. In: Encuentro por una nueva cultura del agua en América Latina, Fortaleza (CE). Anais... Fortaleza, 2005.

PEREIRA, F.; BRAGA, C.; SILVA, A.; AMÉRICO, J. Análise da qualidade e do armazenamento da água consumida na antiga escola agrícola de Ceará-Mirim/RN. In: CONGRESSO DE PESQUISA E INOVAÇÃO DA REDE NORTE NORDESTE DE EDUCAÇÃO TECNOLÓGICA, João Pessoa (PB). Anais... João Pessoa, 2007. 
RIBEIRO, L.L.G. DIREITO À EDUCAÇÃO NA DIVERSIDADE: A PRÁTICA DO BULLYING NO AMBIENTE DA ESCOLA PÚBLICA E A RESPONSABILIDADE DO ESTADO. Revista de Direito Administrativo Contemporâneo 2015 REDAC VOL.21 (NOVEMBRO-DEZEMBRO 2015). Disponível no endereço eletrônico:

http://www.mpsp.mp.br/portal/page/portal/documentacao_e_divulgacao/doc_biblioteca/bibli_ser vicos_produtos/bibli_boletim/bibli_bol_2006/RDAdmCont_n.21.08.PDF., acessado em 18.mar.2018.

SILVA, O.J. Captação de águas pluviais na cidade de Campina Grande (PB): Alternativa para uma política de enfrentamento da escassez de água nas escolas públicas. Dissertação (Mestrado Multidisciplinar em Ciência da Cidadania) - UEPB. Campina Grande, p. 85-PB. 2003.

SILVA, A.S.; PORTO, E.R.; LIMA, L.T.; GOMES, P.C.F. Captação e conservação de água de chuva para consumo humano: cisternas rurais; dimensionamento, construção e manejo. Petrolina, PE: Embrapa - CPATSA, SUDENE, 1984. 103 p. il. (EMBRAPA-CPATSA. Circular Técnica, 12).

SILVA NETO, M.D.; RIOS, M.L.; SANTOS, D.B.; SOUZA M.C. Potencial de captação de água de chuva dos telhados do Instituto Federal Baiano Campus Senhor Do Bonfim. IN: $8^{\circ}$ Simpósio Brasileiro sobre Captação e Manejo de Água de Chuva, Anais... Campina Grande-PB: ABCMAC, p. 14-17. 2012.

SUASSUNA, J. ÁGUA POTÁVEL NO SEMI-ÁRIDO: escassez anunciada. Disponível no endereço eletrônico:

http://www.fundaj.gov.br/index.php?option=com_content\&view=article\&id=736\&ltemid=376 e acessado em 20.out.2018.

VASCONCELOS, L.F.; FERREIRA, O.M. Captação de água de chuva para o uso domiciliar: estudo de caso, 2007. Disponível em: http://www.pucgoias.edu.br /ucg/prope/cpgss/ArquivosUpload/36/file/CAPTA\%C3\%87. Acesso em 07 de março de 2018. 